\title{
Hans-Peter Kreplin, retired
}

\author{
Rolf Henke
}

Published online: 13 August 2014

(c) Deutsches Zentrum für Luft- und Raumfahrt e.V. 2014

In November 2009, Hans-Peter Kreplin launched the CEAS Aeronautical Journal as Managing Editor together with Joachim Szodruch then CEAS President and Andreas Dillmann as Chief Editor. Thanks to his experience, reputation and network, the first printed issue was published already in September 2011. Since then ten more issues have followed and the journal's impact has been continuously growing. On 31 May 2014, Hans-Peter Kreplin retired, and I would like to take the opportunity to thank Hans-Peter for his engagement and successful contributions to establish the CEAS Aeronautical Journal in the scientific and industrial community.

Göttingen is recognised as the birthplace of modern aerodynamics, and it was also the place Hans-Peter Kreplin chose to study physics focusing on fluid mechanics. He started his scientific career with "An Experimental Investigation of the Streamwise and Spanwise Velocity Fluctuations in a Turbulent Channel Flow", ${ }^{1}$ which led to his $\mathrm{PhD}$ in 1976. Thanks to his excellent skills, the German Aerospace Centre, at that time called "German Aerospace Research and Testing Establishment" (DFVLR), recruited him for the Boundary-layer Research Department of the Institute of Fluid Mechanics. Testing with surface hot-film and hot-wire sensors was his main topic since then, and Hans-Peter Kreplin became an internationally renowned expert for experimental aerodynamics.

In 1980, the Heinz Maier-Leibnitz Prize was awarded to Hans-Peter Kreplin (together with Hermann Fasel and Uwe Dallmann) in recognition of his excellent research work. It is the most important prize for outstanding young scientists

R. Henke $(\bowtie)$

German Aerospace Center (DLR), Linder Höhe, 51147 Cologne, Germany

e-mail: Rolf.Henke@dlr.de in Germany, donated by the Federal Ministry of Education and Research together with the German Research Foundation (DFG).

In 1984/85, Hans-Peter Kreplin spent a year at California State University in Long Beach (USA) as part of a research programme of the National Science Foundation working on high-lift configurations. This international experience made him even more of a valuable partner for activities like the international Action Group AD/AG07: "3D Turbulent Shear Laver Experiment" of GARTEUR (Group for Aeronautical Research and Technology in Europe) from 1986 onwards. The goal was to obtain "reliable and detailed mean flow and turbulence data in the 3D boundary layers and the wake of a swept wing at close to those on modern aircrafts at transonic speeds". 2

As Deputy Head of Department at DLR, he participated in a lot of challenging test programmes with large-scale wind-tunnel and flight experiments, for example TLF (Transonic Laminar Wing), involving DLR's then flying test bed ATTAS (Advanced Technologies Testing Aircraft System), a twin-engine VFW 614 short-haul jet converted into a research aircraft. Within one of the first large European aeronautical research projects, ELFIN (European Laminar Flow Investigation), which started in 1989, he was involved into large-scale, complex wind-tunnel tests with hybrid laminar flow wing models as well as flight tests of a laminar part-span wing glove on a Fokker F100 aircraft. In these days I got to know Hans-Peter Kreplin and instantly

\footnotetext{
1 "Experimentelle Untersuchungen der Längsschwankungen und der wandparallelen Querschwankungen der Geschwindigkeit in einer turbulenten Kanalströmung”, Göttingen, 1976.

${ }^{2}$ http://ec.europa.eu/research/growth/aeronautics-days/pdf/posters/ garteur4.pdf.
} 
appreciated his outstanding competence and his friendly nature.

In the following years, he was managing numerous scientific programmes mostly in cooperation with other research facilities and the aeronautical industry, e.g., tests of high-lift configurations in the German-Dutch wind tunnel (DNW). Later on, he became increasingly involved in European research projects (e.g., COSTWING, AEROMEMS II, EUROLIFT). In the Institute, he became more and more committed to take care of visiting scientists and to share his knowledge with young researchers. Since 2007 he was a member of the management board of DLR's Institute of Flow Technology. He held lectures at TU Hannover and TU Clausthal, and he is still dedicated to inspire children and young people for physics and aerodynamics.
Hans-Peter Kreplin's experimental research work was trend-setting in fluid mechanic modelling and flow control, and he published a large number of high-quality and often quite fundamental papers which have been influencing to generations of scientists.

On behalf of the Editorial Board, I greatly appreciate Hans-Peter Kreplin's commitment and dedication to the CEAS Aeronautical Journal during those difficult first years after the launch and I would like to express my sincere gratitude to him, wishing him well for his new phase of life (perhaps with reasonable time to play Hockey).

\section{Rolf Henke}

Editor-in-Chief 